\title{
Novel iridium (III)-derived organometallic compound for the inhibition of human platelet activation
}

\author{
KOU-GI SHYU ${ }^{1,2}$, MARAPPAN VELUSAMY ${ }^{3}$, CHIH-WEI HSIA ${ }^{2}$, CHIH-HAO YANG $^{2}$, CHIH-HSUAN HSIA ${ }^{2}$, \\ DUEN-SUEY CHOU ${ }^{2}$, THANASEKARAN JAYAKUMAR ${ }^{2}$, JOEN-RONG SHEU ${ }^{2}$ and JIUN-YI LI ${ }^{2,4}$
}

\begin{abstract}
${ }^{1}$ Division of Cardiology, Shin Kong Wu Ho-Su Memorial Hospital, Taipei $111 ;{ }^{2}$ Graduate Institute of Medical Sciences and Department of Pharmacology, School of Medicine, College of Medicine, Taipei Medical University, Taipei 110, Taiwan, R.O.C.; ${ }^{3}$ Department of Chemistry, North Eastern Hill University, Shillong, Meghalaya 793022, India; ${ }^{4}$ Department of Cardiovascular Surgery, Mackay Memorial Hospital, and Mackay Medical College, Taipei 104, Taiwan, R.O.C.
\end{abstract}

Received August 31, 2017; Accepted February 2, 2018

DOI: $10.3892 / \mathrm{ijmm} .2018 .3472$

\begin{abstract}
Since cisplatin achieved clinical success, transition metal platinum $(\mathrm{Pt})$ drugs have been effectively used for the treatment of cancer. Iridium (Ir) compounds are considered to be potential alternatives to Pt compounds, as they possess promising anticancer effects with minor side effects. Platelet activation is associated with the metastasis and progression of cancer, and also with arterial thrombosis. Therefore, it is necessary to develop novel, effective antithrombotic agents. An Ir (III)-derived complex, [Ir (Cp*) 1-(2-pyridyl)-3-(3-methoxyphenyl)imidazo[1,5-a]pyridine $\mathrm{Cl}] \mathrm{BF}_{4}(\mathrm{Ir}-3)$, was developed as a novel antiplatelet drug. Ir-3 exerted more potent inhibitory activity on platelet aggregation stimulated by collagen compared with other agonists, including thrombin. In collagen-activated platelets, Ir-3 also inhibited adenosine trisphosphate release, intracellular $\mathrm{Ca}^{+2}$ mobilization and surface $\mathrm{P}$-selectin expression, as well as the phosphorylation of phospholipase $\mathrm{C} \gamma 2$ (PLC $\gamma 2)$, protein kinase $\mathrm{C}$ (PKC), protein kinase B (Akt) and c-Jun N-terminal kinase (JNK) 1, but not p38 mitogen-activated protein kinase or extracellular signal-regulated kinases. Ir-3 did not markedly affect phorbol 12, 13-dibutyrate-stimulated platelet aggregation. Neither the adenylate cyclase inhibitor SQ22536 nor the guanylate cyclase inhibitor $1 \mathrm{H}-[1,2,4]$ oxadiazolo [4,3-a]quinoxalin-1-one significantly reversed the Ir-3-mediated inhibition of platelet
\end{abstract}

Correspondence to: Dr Joen-Rong Sheu, Graduate Institute of Medical Sciences, College of Medicine, Taipei Medical University, $250 \mathrm{Wu}$-Hsing Street, Taipei 110, Taiwan, R.O.C.

E-mail: sheujr@tmu.edu.tw

Dr Jiun-Yi Li, Department of Cardiovascular Surgery, Mackay Memorial Hospital, and Mackay Medical College, 92 Chung-Shan North Road, Section 2, Taipei 104, Taiwan, R.O.C.

E-mail: jyl5891@gmail.com

Key words: Ir (III)-derived complex, platelet activation, phospholipase $\mathrm{C} \gamma 2$-protein kinase $\mathrm{C}$ cascade, protein kinase $\mathrm{B}$, c-Jun N-terminal kinase 1 aggregation. Furthermore, Ir-3 had no considerable diminishing effects on $\mathrm{OH}$ radical signals in collagen-stimulated platelets or Fenton reaction solution. In conclusion, Ir-3 serves a novel function in the inhibition of platelet aggregation through inhibiting the PLC $\gamma 2$-PKC cascade, and the subsequent suppression of Akt and JNK1 activation. Therefore, Ir-3 may be a potential novel therapeutic agent for the treatment of thromboembolic disorders, or the interplay between platelets and tumor cells which contributes to tumor cell proliferation and progression.

\section{Introduction}

Platelets are anucleate blood cells which serve crucial functions in thrombosis under physiological and pathological conditions. They are critical for maintaining the integrity of the vascular system and are the first-line defense against hemorrhage. On encountering subendothelial matrix exposed by an injury to a vessel, platelets adhere to the matrix, are activated and become adhesive to other platelets, leading to further aggregation (1). Platelets are involved in the pathogenesis of atherosclerosis-associated diseases, including coronary artery diseases and stroke. During platelet activation, the release of several mediators, including adenosine trisphosphate (ATP) and thromboxane $\mathrm{A}_{2}$, occurs in conjunction with relative intracellular $\mathrm{Ca}^{+2}\left(\left[\mathrm{Ca}^{+2}\right] \mathrm{i}\right)$ mobilization, attracting additional platelets towards the injured endothelium and resulting in the thickening of the initial platelet monolayer. Finally, fibrinogen binds to its specific platelet receptor, completing the final common pathway for platelet aggregation.

Platelet activation has also been associated with the key steps of cancer progression, and platelets have been proposed to influence the development of malignancies via regulated events that may trigger the pathobiology of cancer growth (2). Platelets also interact with cancer cells and contribute to the critical steps of cancer metastasis, including tumor cell migration, invasion, and arresting of the tumor cell within the vasculature $(2,3)$. During platelet activation, their contents may be released into the peritumoral space and subsequently enhance tumor cell extravasation and metastasis (4). 
The chemically similar platinum $(\mathrm{Pt})$ group elements (PGEs), including Pt, palladium, rhodium, ruthenium, osmium, and iridium (Ir), have exceptional catalytic qualities. These metals are resistant to chemical corrosion over a wide range of temperatures, having a high melting point, high mechanical strength and remarkable ductility (5). Ir is rich in the Earth's crust, with an average mass fraction of $1 \mu \mathrm{g} / \mathrm{kg}$ in crustal rock. In nature, Ir is found in alluvium deposits accompanied by $\mathrm{Pt}$ and other PGEs. This metal is obtained from Pt ores, and is also derived as a by-product in nickel mining and industry (6). Various metal complexes have been identified for use in anticancer therapy, leading to an increasing amount of associated research. In the drug development industry, metal complexes represent a highly resourceful platform. Apart from deviations in the metal and oxidation state, metal ions have variable geometries and coordination numbers that allow the modification of their chemical reactivity in terms of kinetics (ligand exchange rates) and thermodynamics (including metal-ligand bond strength and redox potentials). Metals, as well as their ligands, are involved in numerous biological activities, ranging from outer-sphere recognition of target sites to the activity of any released ligands and ligand-centered redox processes (7).

Organometallic Ir (III) complexes are particularly promising in terms of anticancer treatments. Previous research has focused on Ir (III) compounds due to their potential antitumor activity and low toxicity towards normal tissues $(8,9)$. Furthermore, Ir complexes exert potent antiangiogenic effects by activating distinct antiangiogenic signaling pathways (8), and antiangiogenic therapy is considered a promising cancer treatment strategy. On the basis of these observations, our group obtained novel biologically active Ir (III) derivatives by developing a new Ir (III) compound, also referred to as Ir-3 (Fig. 1). Although certain experimental and animal studies have demonstrated that Ir-based compounds have potent anticancer activity, to date, no study has investigated their effects on platelet aggregation. The preliminary results of the present study revealed that Ir-3 exhibits potent antiplatelet activity in humans, encouraging further examination of the characteristics and functional activity of Ir-3 in platelet activation. The results of the present study provide valuable evidence for the development of a novel class of Ir-3-based antiplatelet agents.

\section{Materials and methods}

Chemicals and reagents. Thrombin, collagen, arachidonic acid (AA), luciferin-luciferase, U46619, phorbol 12,13-dibutyrate (PDBu), nitroglycerin (NTG), heparin, prostaglandin $\mathrm{E}_{1}\left(\mathrm{PGE}_{1}\right)$, 5,5-dimethyl-1-pyrroline N-oxide (DMPO), SQ22536, 1H-[1,2,4]oxadiazolo[4,3-a]quinoxalin-1-one (ODQ), and bovine serum albumin (BSA) were purchased from Sigma-Aldrich; Merck KGaA (Darmstadt, Germany). Fura-2AM was obtained from Molecular Probes; Thermo Fisher Scientific, Inc. (Waltham, MA, USA). Anti-phosphorylated (p)-p38 mitogen-activated protein kinase (MAPK) Thr180/Tyr182 monoclonal antibodies (mAbs; Cat. no. 9211) were purchased from Santa Cruz Biotechnology, Inc. (Dallas, TX, USA). Anti-p38 MAPK (Cat. no. 9217), anti-p-c-Jun N-terminal kinase (JNK; Thr183/Tyr185; Cat. no. 9251), and anti-p44/42 extracellular signal-regulated kinase (ERK) mAbs (Cat. no. 9107), as well as anti-phospholipase $\mathrm{C} \gamma 2$ (PLC $\gamma 2$; Cat. no. 3872), anti-p-(Tyr759) PLC $\gamma 2$ (Cat. no. 3874), anti-p-(Ser) protein kinase C (PKC) substrate (pleckstrin; p-p47; Cat. no. 2261), anti-JNK (Cat. no. 9252), and anti-p-p44/p42 ERK (Thr202/Tyr204) polyclonal antibodies (pAbs; Cat. no. 9101) were purchased from Cell Signaling Technology, Inc. (Danvers, MA, USA). Anti-p-protein kinase B (Akt) (Ser473; Cat. no. 9271) and anti-Akt mAbs (Cat. no. 2920) were purchased from Biovision (Mountain View, CA, USA). An anti-pleckstrin (p47) pAb (Cat. no. GTX17020) was purchased from Gene Tex (Irvine, CA, USA). A Hybond-P polyvinylidene fluoride (PVDF) membrane, an enhanced chemiluminescence western blotting detection reagent, horseradish peroxidase (HRP)-conjugated donkey anti-rabbit immunoglobulin $\mathrm{G}$ (IgG; Cat. no. RPN4301) and sheep anti-mouse IgG (Cat. no. RPN4201) were purchased from GE Healthcare Life Sciences (Little Chalfont, UK). A fluorescein isothiocyanate (FITC)-conjugated anti-human CD42P (P-selectin) $\mathrm{mAb}$ (Cat. no. 304904) was obtained from Bio Legend, Inc. (San Diego, CA, USA).

Synthesis of 1-(2-pyridyl)-3-(3-methoxyphenyl)imidazo[1,5-a] pyridine $(L)$. Ammonium acetate $(1.93 \mathrm{~g}, 25 \mathrm{mM}), 4$-methoxy benzaldehyde $(1.02 \mathrm{~g}, 7.5 \mathrm{mM})$ and glacial acetic acid $(25 \mathrm{ml})$ were added to a degassed mixture of di-pyridin-2-yl-methanone $(0.9 \mathrm{~g}, 5 \mathrm{mM})$, and the mixture was placed in an oil bath maintained at $120^{\circ} \mathrm{C}$ under a nitrogen atmosphere for $18 \mathrm{~h}$. The reaction mixture was then cooled to room temperature, poured into ice cold water, and extracted with chloroform $(3 \times 70 \mathrm{ml})$. The organic layer was dried over anhydrous sodium sulfate, and then filtered. The residue was chromatographed through silica gel (ethylacetate/hexane $=1: 3$ ) to yield a yellow solid. The characteristics of this solid were as follows: Melting point: $105-110^{\circ} \mathrm{C} ;{ }^{1} \mathrm{H}$ nuclear magnetic resonance (NMR; $400 \mathrm{MHz}$, $\left.\mathrm{CDCl}_{3}\right): \delta 8.72-8.70(\mathrm{~d}, 1 \mathrm{H}, J=8 \mathrm{~Hz}), 8.65-8.64(\mathrm{~d}, 1 \mathrm{H}, J=4 \mathrm{~Hz})$, 8.27-8.25 (d, $1 \mathrm{H}, J=8 \mathrm{~Hz}), 8.2-8.19$ (d, $1 \mathrm{H}, J=8 \mathrm{~Hz}), 7.78-7.73$ $(\mathrm{t}, 3 \mathrm{H}, J=10 \mathrm{~Hz}), 7.13-7.07(\mathrm{~m}, 3 \mathrm{H}, J=8 \mathrm{~Hz}), 6.96-6.92(\mathrm{t}, 1 \mathrm{H}$, $J=8 \mathrm{~Hz}), 6.67-6.64(\mathrm{t}, 1 \mathrm{H}, J=6 \mathrm{~Hz}), 3.9(\mathrm{~s}, 3 \mathrm{H}) ;{ }^{13} \mathrm{C} \mathrm{NMR}$ $\left(400 \mathrm{MHz}, \mathrm{CDCl}_{3}\right)$ 160.0, 155.1, 148.9, 138.0, 136.1, 130.1, 129.9, 129.7, 122.5, 121.7, 121.5, 120.8, 120.3, 119.8, 114.4, 113.6, 55.3; ultraviolet-visible spectrophotometry (UV-Vis; $\lambda_{\text {abs }}, \mathrm{nm}$ ): $380,321,300,238$; electrospray ionization-mass spectrometry (ESI-MS; m/z): $301\left(\mathrm{M}^{+}\right)$.

Synthesis of $\left[\operatorname{Ir}\left(C p^{*}\right)(L) C l\right] B F_{4}(\operatorname{Ir}-3) \cdot\left[\operatorname{Ir}\left(\mathrm{Cp}^{*}\right)(\mathrm{Cl})_{2}\right]_{2}(0.16 \mathrm{~g}$, $0.2 \mathrm{mM})$ in methanol $(10 \mathrm{ml})$ solution was added dropwise to $10 \mathrm{ml}$ methanolic solution of 1-(2-pyridyl)-3-(3-methoxyphenyl)imidazo[1,5-a]pyridine (L) (0.12 g, $0.4 \mathrm{mM})$, and the solution was stirred at room temperature for $3 \mathrm{~h}$. Subsequently, $\mathrm{NH}_{4} \mathrm{BF}_{4}(200 \mathrm{mg}, 0.60 \mathrm{mM})$ was added to the initial pale yellow solution, changing the color to orange. After $24 \mathrm{~h}$, the solution was evaporated and the solid obtained was filtered. The residue was washed with diethyl ether $(40 \mathrm{ml})$ and dried under a vacuum. The desired product was recrystallized from the dichloromethane/hexane mixture, yielding orange microcrystals. The characteristics of this solid were as follows: ${ }^{1} \mathrm{H}$ NMR (400 MHz, dimethyl sulfoxide [DMSO]-D6): $\delta 8.82-8.81$ $(\mathrm{d}, 1 \mathrm{H}, \mathrm{J}=4 \mathrm{~Hz}), 8.52-8.39(\mathrm{~m}, 3 \mathrm{H}), 8.17-8.10(\mathrm{~m}, 3 \mathrm{H}), 7.54-7.47$ (m, 2H), 7.31-7.29 (d, 2H, J=8 Hz), 7.15-7.11 (t, $1 \mathrm{H}, J=8 \mathrm{~Hz})$, $3.90(\mathrm{~s}, 3 \mathrm{H}), 1.29(\mathrm{~s}, 15 \mathrm{H})$; UV-Vis $\left(\lambda_{\text {abs }}, \mathrm{nm}\right)\left(\varepsilon, \mathrm{M}^{-1} \mathrm{~cm}^{-1}\right)$ : 


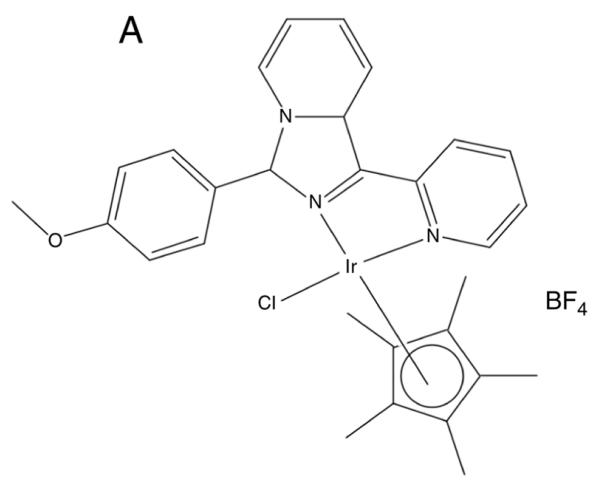

$\left(\mathrm{Ir}-3, \mathrm{C}_{29} \mathrm{H}_{32} \mathrm{BCIF}_{4} \mid \mathrm{rN} \mathrm{N}_{3} \mathrm{O}, \mathrm{MW}: 756.03\right)$

B<smiles>COc1ccc(C=[O+]c2ccc(C(=O)Nc3ccc(-c4nc(-c5ccc(OC)cc5)n5ccccc45)nc3)nc2)cc1</smiles>

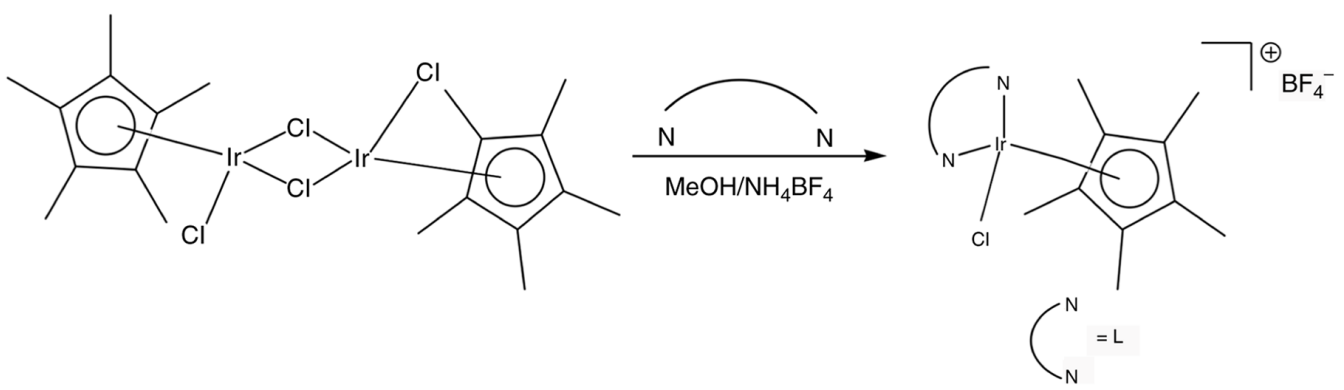

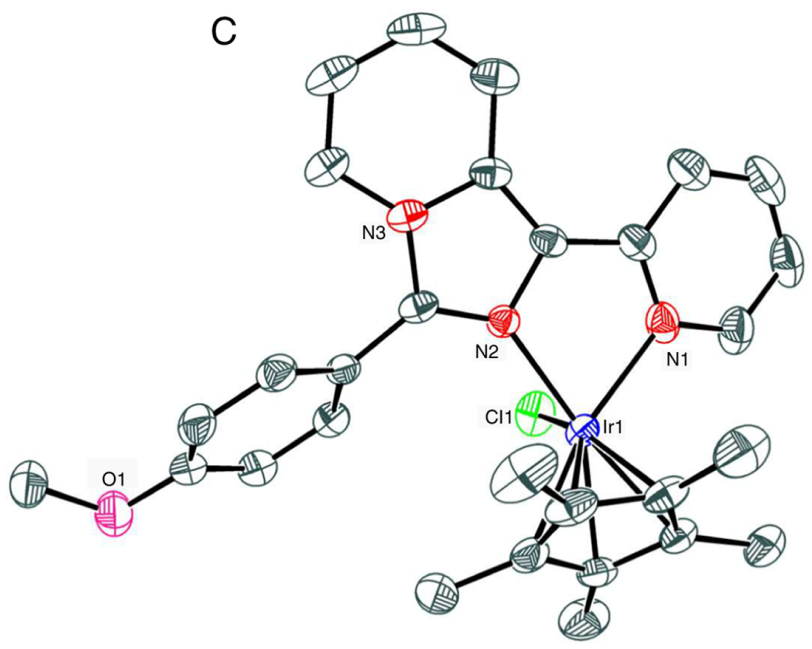

Figure 1. A novel, biologically active Ir (III) compound. (A) Chemical structure of Ir-3 and (B) synthesis of the ligand (L) 1-(2-pyridyl)-3-(3-methoxyphenyl) imidazo[1,5-a]pyridine and complex $(\operatorname{Ir}-3)\left[\operatorname{Ir}(\mathrm{Cp} *)(\mathrm{L}) \mathrm{Cl}_{3} \mathrm{BF}_{4}\right.$. $(\mathrm{C})$ Oak Ridge Thermal Ellipsoid Plot scheme of Ir-3. Hydrogen atoms and the $\mathrm{BF}_{4}$ anion are omitted for clarity.

406 (1649), 385 (2372), 367 (1854), 282 (2871), 242 (2881); ESI-MS (m/z): $664.08\left[\mathrm{M}-B F_{4}\right]^{+}$(Fig. 1).

Platelet aggregation. The present study was approved by the Institutional Review Board of Taipei Medical University (Taipei, Taiwan; approval no. TMU-JIRB-N201612050) and conformed to the directives of the Declaration of Helsinki. All human volunteers involved in the present study provided written informed consent. Human platelet suspensions were prepared as described previously (10). Human blood was collected from 20 healthy individuals (aged between 20 and 30 years old, 12 females and 8 males) of Taipei Medical University who had taken no drugs or other substances that would interfere with the experiment for at least 14 days prior to collection between July 2017 and August 2017. The collected blood was mixed with an acid-citrate-dextrose solution $(9: 1, \mathrm{v} / \mathrm{v})$ and centrifuged at $120 \mathrm{xg}$ for $10 \mathrm{~min}$ at $37^{\circ} \mathrm{C}$ to separate the platelet-rich plasma (PRP). Following centrifugation, the PRP 
was supplemented with $0.5 \mu \mathrm{M} \mathrm{PGE}_{1}$ and $6.4 \mathrm{IU} / \mathrm{ml}$ heparin, incubated for $10 \mathrm{~min}$ at $37^{\circ} \mathrm{C}$ and centrifuged at $500 \mathrm{x} \mathrm{g}$ for $10 \mathrm{~min}$ at room temperature. The collected pellets were mixed with $5 \mathrm{ml}$ Tyrode's solution, $\mathrm{pH} 7.3$ [containing (mM) $\mathrm{NaCl} 11.9, \mathrm{KCl} 2.7, \mathrm{MgCl}_{2} 2.1, \mathrm{NaH}_{2} \mathrm{PO}_{4} 0.4, \mathrm{NaHCO}_{3}$ 11.9, and glucose 11.1]. Then, apyrase $(1.0 \mathrm{U} / \mathrm{ml}), \mathrm{PGE}_{1}(0.5 \mu \mathrm{M})$ and heparin $(6.4 \mathrm{IU} / \mathrm{ml})$ were added, and the mixture was incubated for $10 \mathrm{~min}$ at $37^{\circ} \mathrm{C}$. Following centrifugation of the suspensions at $500 \mathrm{x} \mathrm{g}$ for $10 \mathrm{~min}$ at room temperature, the washing procedure was repeated. The washed platelets were finally suspended in Tyrode's solution containing BSA $(3.5 \mathrm{mg} / \mathrm{ml})$. The final $\mathrm{Ca}^{2+}$ concentration in the Tyrode solution was $1 \mathrm{mM}$. A platelet aggregation test was performed using a Lumi-Aggregometer (Payton Associates, Scarborough, ON, Canada) as described previously (10). Various concentrations of Ir-3 or a solvent control (0.1\% DMSO) were preincubated with platelet suspensions $\left(3.6 \times 10^{8}\right.$ cells $\left./ \mathrm{ml}\right)$ for $3 \mathrm{~min}$ prior to the addition of various concentrations of agonists $(1 \mu \mathrm{g} / \mathrm{ml}$ collagen, $0.01 \mathrm{U} / \mathrm{ml}$ thrombin, $1 \mu \mathrm{M}$ U46619 or $120 \mu \mathrm{M} \mathrm{AA})$. The extent of platelet aggregation was calculated as the percentage with respect to the control (absence of Ir-3) in light transmission units when the reaction had proceeded for $6 \mathrm{~min}$. For an ATP release assay, $20 \mu 1$ luciferin-luciferase was added $1 \mathrm{~min}$ prior to the addition of the agonist, and the amount of ATP released was compared with that released by the control using a Lumi-Aggregometer.

Measurement of $\left[\mathrm{Ca}^{2+}\right]$ i mobilization using Fura-2AM fluorescence. The $\left[\mathrm{Ca}^{2+}\right]$ concentration was measured using the calcium sensitive dye Fura-2AM, as described previously (10). In brief, citrated whole blood was centrifuged at $120 \mathrm{x} \mathrm{g}$ for $10 \mathrm{~min}$ at room temperature, and the supernatant was collected and incubated with $5 \mu \mathrm{M}$ Fura-2AM for $1 \mathrm{~h}$ at $37^{\circ} \mathrm{C}$. The Fura-2AM-preincubated platelets were washed with Tyrode's solution and treated with Ir-3 in the presence of $1 \mathrm{mM}$ $\mathrm{CaCl}_{2}$, and then stimulated with collagen $(1 \mu \mathrm{g} / \mathrm{ml})$. Fura-2 fluorescence was measured using excitation wavelengths of 340 and $380 \mathrm{~nm}$ and emission at $510 \mathrm{~nm}$ with a spectrofluorometer (Hitachi FL Spectrophotometer F-4500; Hitachi, Ltd., Tokyo, Japan).

Detection of lactate dehydrogenase. Washed platelets (3.6x $10^{8}$ cells $\left./ \mathrm{ml}\right)$ were preincubated with $20-100 \mu \mathrm{M} \mathrm{Ir}-3$ or the solvent control ( $0.1 \%$ DMSO) for $20 \mathrm{~min}$ at $37^{\circ} \mathrm{C}$. Following incubation, supernatant $(10 \mu \mathrm{l})$ was added to a Fuji Dri-Chem slide lactate dehydrogenase (LDH)-PIII (Fujifilm Holdings Corporation, Tokyo, Japan). The absorbance of the supernatant was measured at $540 \mathrm{~nm}$ using a UV-Vis spectrophotometer (UV-160; Shimadzu Corporation, Kyoto, Japan). A maximal value of LDH was recorded in platelets lysed with Triton.

Flow cytometric analysis. Platelet surface P-selectin expression was examined using flow cytometric analysis. Washed platelets were prepared as aforementioned. Aliquots of platelet suspensions $\left(3.6 \times 10^{8}\right.$ cells $\left./ \mathrm{ml}\right)$ were treated with either the solvent control (0.1\% DMSO) or Ir-3 (10 and $20 \mu \mathrm{M})$, and FITC-conjugated P-selectin $(2 \mu \mathrm{g} / \mathrm{ml}) \mathrm{mAbs}$ were then added and incubated for $3 \mathrm{~min}$ at $37^{\circ} \mathrm{C}$. This was followed by the addition of collagen $(1 \mu \mathrm{g} / \mathrm{ml})$ to trigger platelet activation, for $1 \mathrm{~min}$ at $37^{\circ} \mathrm{C}$. The suspensions were then assayed for fluorescein-labeled platelets using a flow cytometer (FACScan System; BD Biosciences, San Jose, CA, USA) with FACSuite $^{\mathrm{TM}}$ software (version 1.0.5.3841; BD Biosciences). Data were collected from 50,000 platelets per experimental group, and the platelets were identified on the basis of their characteristic forward and orthogonal light-scattering profiles. All experiments were repeated at least three times to ensure reproducibility.

Western blotting. Washed platelets $\left(1.2 \times 10^{9}\right.$ cells $\left./ \mathrm{ml}\right)$ were preincubated with Ir-3 (10 and $20 \mu \mathrm{M})$ or the solvent control ( $0.1 \% \mathrm{DMSO}$ ) for $3 \mathrm{~min}$ at $37^{\circ} \mathrm{C}$, and $1 \mu \mathrm{g} / \mathrm{ml}$ collagen was added to trigger platelet activation for $5 \mathrm{~min}$ at $37^{\circ} \mathrm{C}$. The reaction was then stopped, and the platelets were immediately resuspended in $200 \mu 1$ lysis buffer [containing (mM) 50 HEPES, 5 EDTA, $50 \mathrm{NaCl}$ and 1\% Triton X-100]. Proteins were quantified using an ELISA reader at $570 \mathrm{~nm}$. Samples containing $80 \mu \mathrm{g}$ of protein were separated through $12 \%$ sodium dodecyl sulfate gel electrophoresis, and the proteins were electrotransferred to PVDF membranes using a Bio-Rad semi-dry transfer unit (Bio-Rad Laboratories, Inc., Hercules, CA, USA). The blots were then blocked with Tris-buffered saline in Tween-20 (TBST; $10 \mathrm{mM}$ Tris-base, $100 \mathrm{mM} \mathrm{NaCl}$, and 0.01\% Tween-20) containing 5\% BSA for $1 \mathrm{~h}$ at room temperature, and probed with the aforementioned primary antibodies (diluted 1:1,000 in TBST) for $2 \mathrm{~h}$ at $4^{\circ} \mathrm{C}$. The membranes were incubated with HRP-conjugated anti-mouse IgG for anti-ERK, anti-p38 and anti-Akt or anti-rabbit IgG for anti-phosphorylated MAPKs, anti-p-Akt, anti-p-PLC $\gamma 2$, anti-PLC $\gamma 2$, anti-p-PKC substrate and anti-JNK (diluted 1:3,000 in TBST) for $1 \mathrm{~h}$ at $4^{\circ} \mathrm{C}$. An enhanced chemiluminescence system was used to detect immunoreactive bands, and their optical density was quantified using Bio-profil Biolight software (version V2000.01; Vilber Lourmat, Marne-la-Vallée, France).

Measurement of $\mathrm{OH}$ radicalformation in platelet suspensions and Fenton reaction solution through electron spin resonance (ESR) spectrometry. Electron spin resonance spectrometry was performed on a Bruker EMX ESR spectrometer (Bruker Corporation, Billerica, MA, USA) as described previously (11). Platelet suspensions $\left(3.6 \times 10^{8}\right.$ cells $\left./ \mathrm{ml}\right)$ or Fenton reaction solution $\left(50 \mu \mathrm{M} \mathrm{FeSO}_{4}+2 \mathrm{mM} \mathrm{H}_{2} \mathrm{O}_{2}\right)$ were preincubated with $0.1 \%$ DMSO or Ir-3 (10 and $20 \mu \mathrm{M})$ for $3 \mathrm{~min}$ at room temperature, with or without the addition of $1 \mu \mathrm{g} / \mathrm{ml}$ collagen. Following incubation of the suspensions for $5 \mathrm{~min}$, $100 \mu \mathrm{M}$ DMPO was added prior to the execution of ESR spectrometry. The ESR spectra were recorded using a quartz flat cell designed for aqueous solutions. The spectrometer was operated at a power of $20 \mathrm{~mW}$, frequency of $9.78 \mathrm{GHz}$, scan range of $100 \mathrm{G}$ and receiver gain of $5 \times 10^{4}$. The modulation amplitude was $1 \mathrm{G}$, the time constant was $164 \mathrm{~ms}$, and scanning was performed for $42 \mathrm{sec}$, with the spectra being the sum of three scans.

Statistical analysis. The experimental results are expressed as the mean \pm standard error of the mean, and are accompanied by the number of observations (n). The $n$ values refer to the number of experiments, and each experiment was conducted using different blood donors. The between-group differences in the experiments were assessed through one-way analysis of 
A
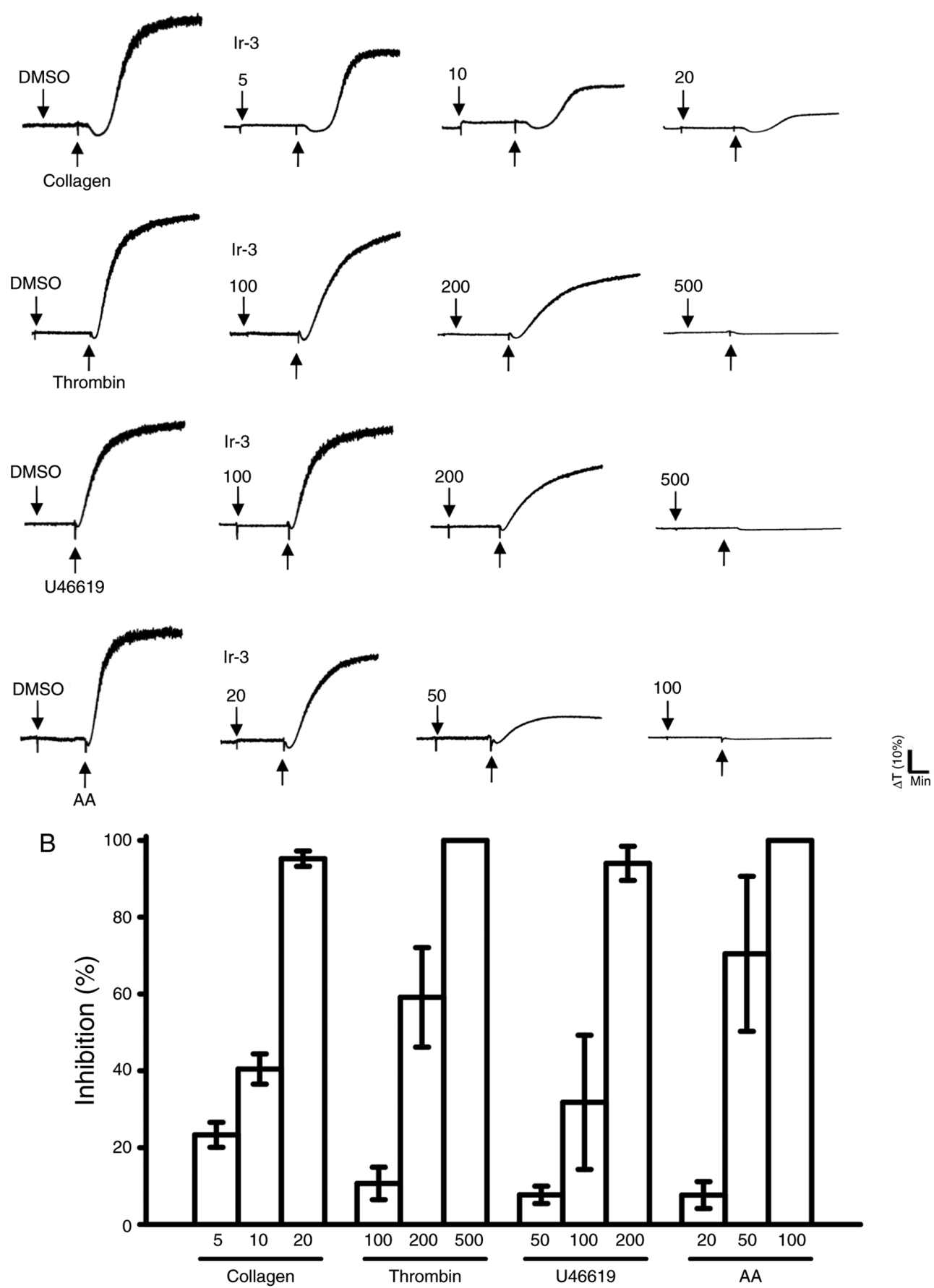

Figure 2. Comparison of the relative inhibitory activity of Ir-3 against platelet aggregation stimulated by various agonists in washed human platelets. (A) Washed human platelets $\left(3.6 \times 10^{8}\right.$ cells $\left./ \mathrm{ml}\right)$ were pre-incubated with the solvent control $(0.1 \%$ DMSO) or Ir-3 (5-100 $\mu \mathrm{M})$ and subsequently treated with $1 \mu \mathrm{g} / \mathrm{ml}$ collagen, $0.01 \mathrm{U} / \mathrm{ml}$ thrombin, $1 \mu \mathrm{M}$ U46619 or $120 \mu \mathrm{M}$ AA to stimulate platelet aggregation. (B) Concentration-response histograms of Ir-3 against platelet aggregation stimulated by the indicated agonists. Data are presented as the mean \pm standard error of the mean (n=3). AA, arachidonic acid.

variance (ANOVA). When the ANOVA indicated significant differences among the group means, the groups were compared using the Student-Newman-Keuls method. Statistical analyses were performed using SAS (version 9.2; SAS Institute, Inc., Cary, NC, USA). $\mathrm{P}<0.05$ was considered to indicate a statistically significant difference.

\section{Results}

Inhibitory effects of Ir-3 on platelet aggregation in washed human platelets. Ir-3 (5-20 $\mu \mathrm{M}$; Fig. 2) inhibited platelet aggregation in collagen $(1 \mu \mathrm{g} / \mathrm{ml})$-stimulated human platelets in a concentration-dependent manner. Ir-3 (20-100 $\mu \mathrm{M})$ demonstrated moderate activity against platelet aggregation in platelets stimulated by $120 \mu \mathrm{M}$ AA. Furthermore, Ir-3 $(100-500 \mu \mathrm{M})$ had relatively weak activity against $0.01 \mathrm{U} / \mathrm{ml}$ thrombin or $1 \mu \mathrm{M}$ U46619, a prostaglandin endoperoxide stimulant, indicating that Ir-3 had more potent inhibitory activity against collagen stimulation compared with other agonists (Fig. 2B). The solvent control, 0.1\% DMSO, did not affect platelet aggregation (Fig. 2A). Furthermore, aspirin (20, 50 and $100 \mu \mathrm{M})$ inhibited platelet aggregation stimulated 
A

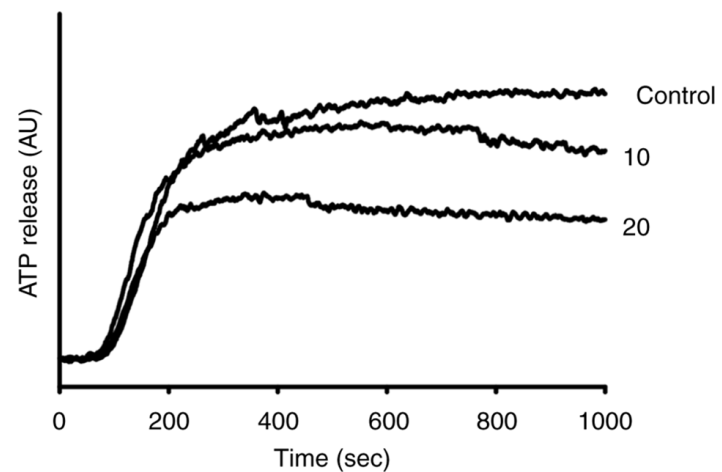

B

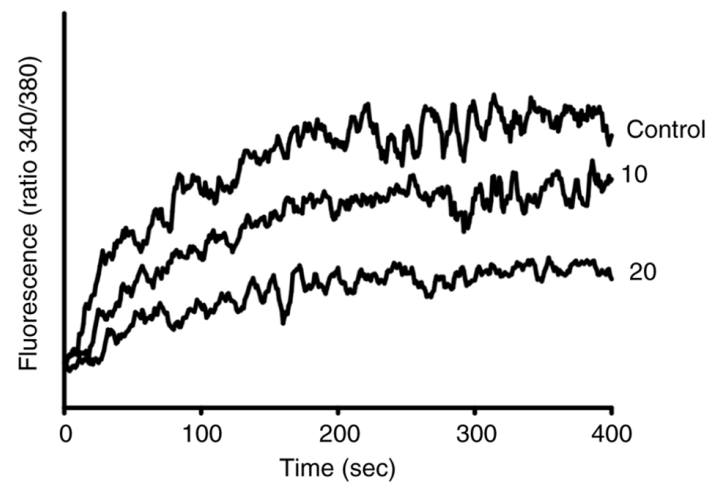

C

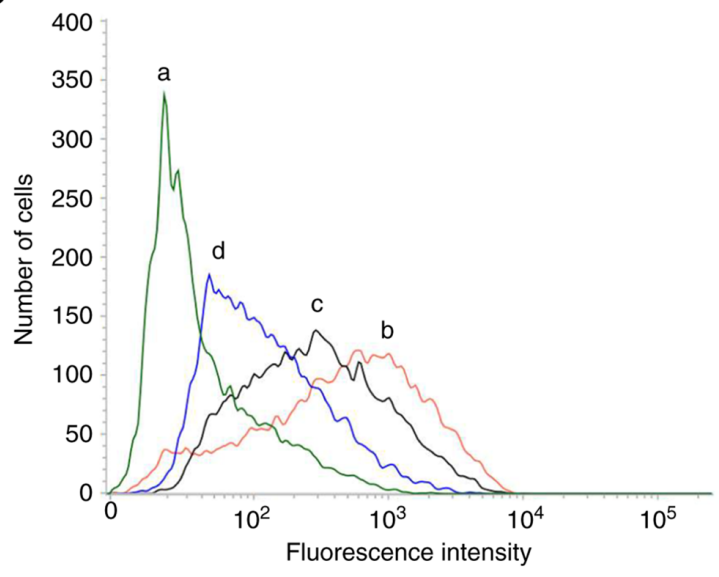

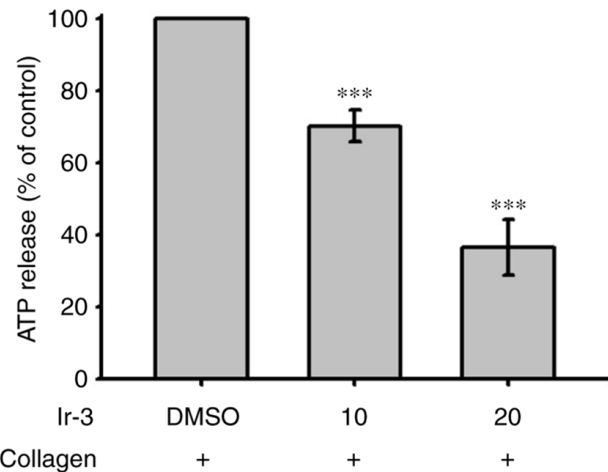
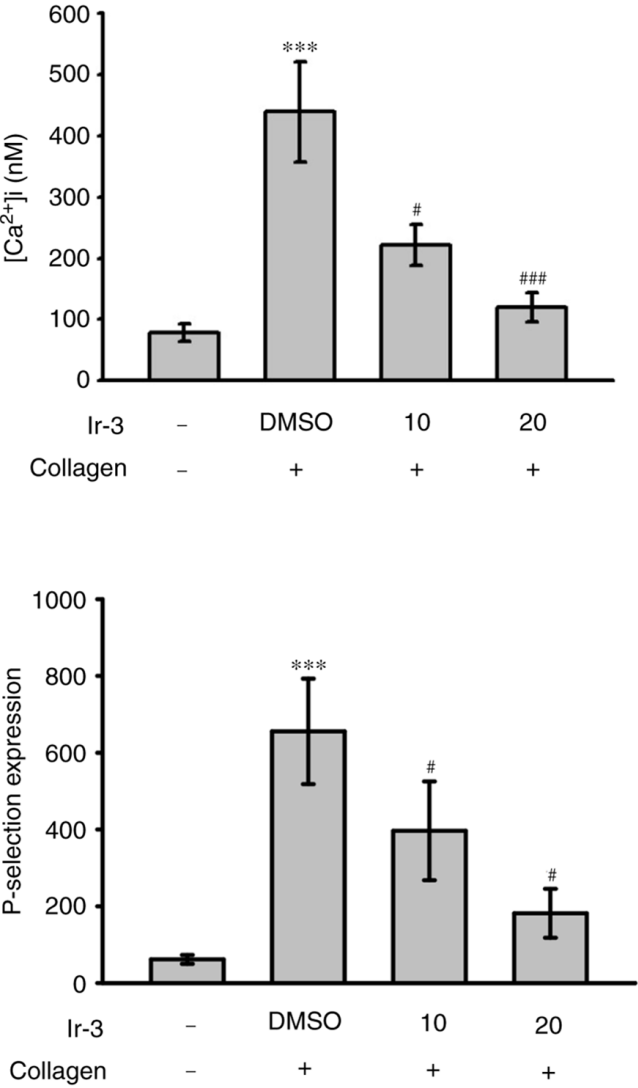

Figure 3. Effects of Ir-3 on ATP release, relative $\left[\mathrm{Ca}^{2+}\right]$ mobilization and surface FITC-P-selectin expression in human platelets. Washed platelets $\left(3.6 \times 10^{8}\right.$ cells $\left./ \mathrm{ml}\right)$ were pre-incubated with the solvent control $(0.1 \%$ DMSO) or Ir-3 (10 and $20 \mu \mathrm{M})$, and collagen $(1 \mu \mathrm{g} / \mathrm{ml})$ was added to trigger either $(\mathrm{A})$ the ATP release reaction or (B) relative $\left[\mathrm{Ca}^{2+}\right]$ mobilization. (C) Washed platelets $\left(3.6 \times 10^{8} / \mathrm{ml}\right)$ were preincubated with the solvent control (0.1\% DMSO) or Ir-3 $(10$ and $20 \mu \mathrm{M})$ and FITC-P-selectin $(2 \mu \mathrm{g} / \mathrm{ml})$ for $3 \mathrm{~min}$ and then stimulated by collagen $(1 \mu \mathrm{g} / \mathrm{ml})$. The corresponding statistical data are presented in the right panel of each Figure section. Data are presented as the means \pm standard error of the mean $(n=3)$. ${ }^{* * *} \mathrm{P}<0.001$ vs. the DMSO-treated group in section A or resting control in section $\mathrm{B}$ and $\mathrm{C} ;{ }^{\#} \mathrm{P}<0.05$ and ${ }^{\# \# \#} \mathrm{P}<0.001$ vs. the DMSO-treated group in sections $\mathrm{B}$ and $\mathrm{C}$. ATP, adenosine trisphosphate; FITC, fluorescein isothiocyanate; $\mathrm{AU}$, arbitrary unit.

by $1 \mu \mathrm{g} / \mathrm{ml}$ collagen in a concentration-dependent manner, with a half maximal inhibitory concentration of $\sim 50 \mu \mathrm{M}(\mathrm{n}=3$; data not shown). Therefore, Ir-3 is $\sim 5$ times more potent than aspirin at inhibiting collagen-stimulated platelet aggregation. In the following experiments, $1 \mu \mathrm{g} / \mathrm{ml}$ collagen was used as an agonist for investigating potential inhibitory mechanisms of Ir-3 in human platelets.

Effects of Ir-3 on ATP release reaction, relative $\left[\mathrm{Ca}^{+2}\right]$ mobilization and surface $P$-selectin expression. The activation of platelets releases the granular contents, including adenosine diphosphate (ADP)/ATP and $\mathrm{Ca}^{+2}$ from the dense granules, and surface P-selectin from the $\alpha$-granules, to the external environment where they are involved in substantial platelet aggregation. In the present study, Ir-3 (10 and $20 \mu \mathrm{M})$ inhibited the ATP release reaction $(10 \mu \mathrm{M}, 33.2 \pm 1.1 \% ; 20 \mu \mathrm{M}$, $67.8 \pm 3.7 \%$; Fig. $3 \mathrm{~A}$ ) and relative $\left[\mathrm{Ca}^{2+}\right]$ i mobilization (resting

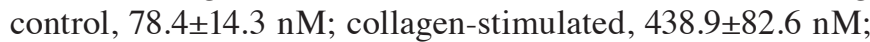
$10 \mu \mathrm{M}, 221.9 \pm 33.3 \mathrm{nM} ; 20 \mu \mathrm{M}, 119.1 \pm 23.8 \mathrm{nM}$; n=3, Fig. 3B) in platelets stimulated by $1 \mu \mathrm{g} / \mathrm{ml}$ collagen. The corresponding statistical data are presented in the right panels of Fig. 3. In quiescent platelets, P-selectin is located on the inner wall of the $\alpha$-granules. Platelet activation exposes the inner walls of the granules to the outside of the cell (12). Ir-3 treatment 
A
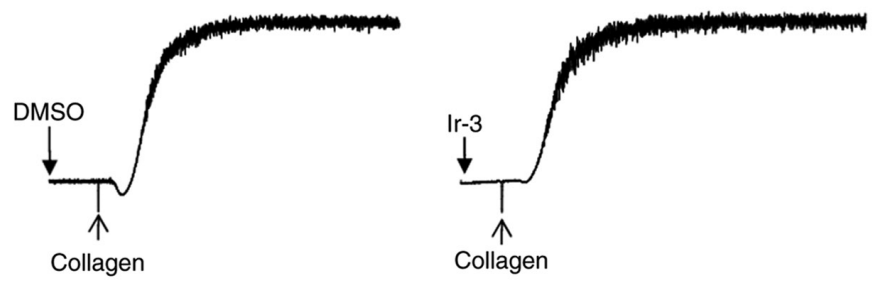

B
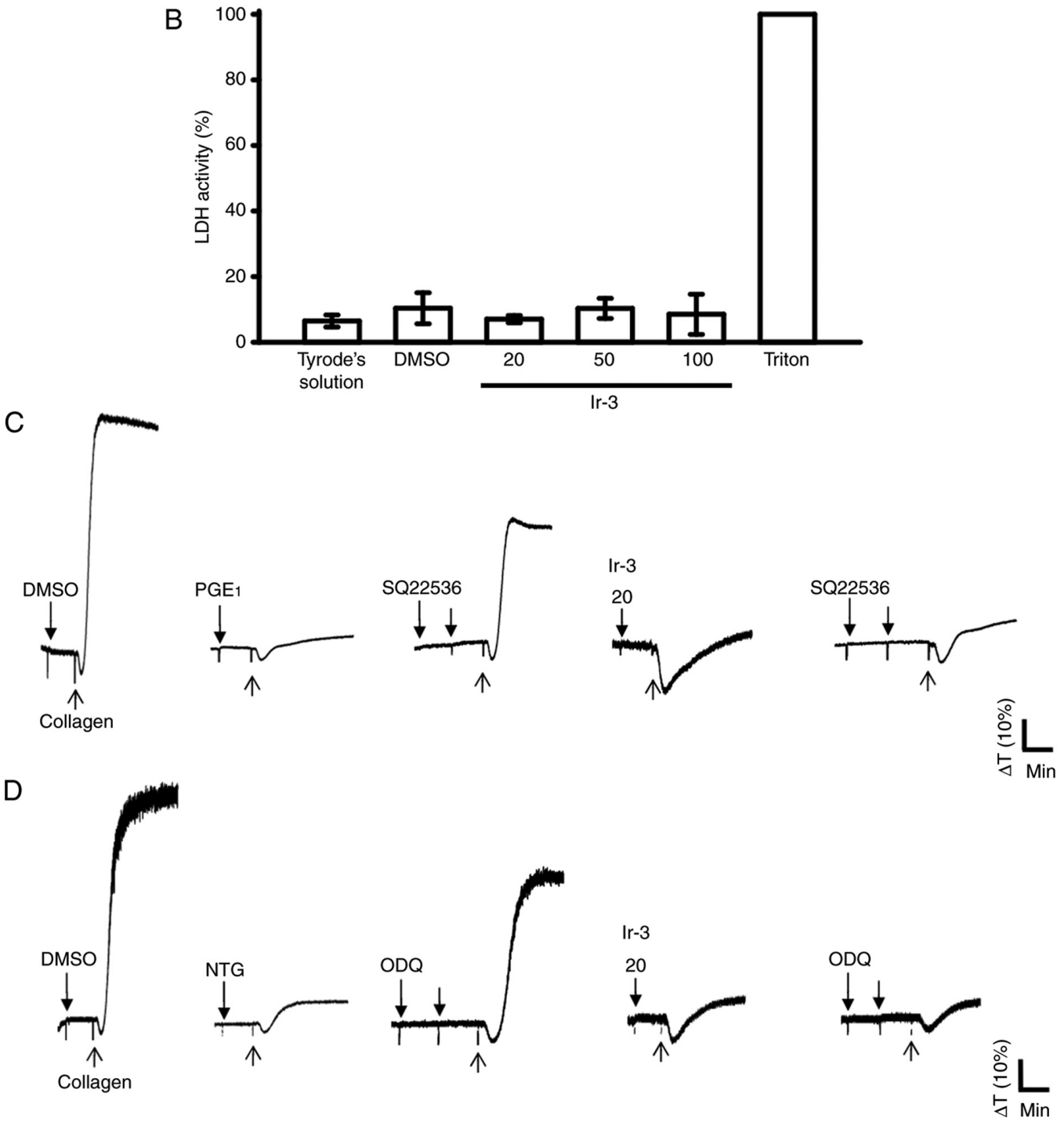

Figure 4. Influence of Ir-3 on cytotoxicity, LDH release and cyclic nucleotide formation in human platelets. (A) Washed platelets were pre-incubated with the solvent control $(0.1 \%$ DMSO) or Ir-3 $(100 \mu \mathrm{M})$ for $10 \mathrm{~min}$ and subsequently washed two times with Tyrode's solution. Collagen $(1 \mu \mathrm{g} / \mathrm{ml})$ was then added to trigger platelet aggregation. (B) Washed platelets $\left(3.6 \times 10^{8} / \mathrm{ml}\right)$ were pre-incubated with the solvent control $(0.1 \%$ DMSO) or Ir-3 (20, 50, and $100 \mu \mathrm{M})$ for $20 \mathrm{~min}$, and a 10- $\mu 1$ aliquot of the supernatant was deposited on a Fuji Dri-Chem slide LDH-PIII. For other experiments, washed platelets $\left(3.6 \times 10^{8}\right.$ cells $\left./ \mathrm{ml}\right)$ were pre-incubated with (C) $1 \mu \mathrm{M} \mathrm{PGE}_{1}$, (D) $10 \mu \mathrm{M} \mathrm{NTG,} \mathrm{or} \mathrm{Ir-3}(20 \mu \mathrm{M})$ in the absence or presence of $100 \mu \mathrm{M}$ SQ22536 or $10 \mu \mathrm{M}$ ODQ, and were subsequently treated with $1 \mu \mathrm{g} / \mathrm{ml}$ collagen to induce platelet aggregation. Data are presented as the mean \pm standard error of the mean ( $\mathrm{n}=3$ ). Profiles in sections A, C and D represent the four independent experiments. $\mathrm{LDH}$, lactate dehydrogenase; $\mathrm{PGE}_{1}$, prostaglandin $\mathrm{E}_{1}$; NTG, nitroglycerin; ODQ, 1H-[1,2,4] oxadiazolo[4,3-a]quinoxalin-1-one.

significantly reduced collagen-induced surface P-selectin expression, as demonstrated by the corresponding statistical data in the right panel (resting control, $61.7 \pm 11.5$; collagen-activated, 655.7 $\pm 137.3 ; 10 \mu \mathrm{M}, 396.7 \pm 128.8 ; 20 \mu \mathrm{M}, 181.7 \pm 63.8$; $\mathrm{n}=3$; Fig. 3C).

Influence of Ir-3 on LDH release and cyclic nucleotide formation in washed human platelets. The aggregation curves of platelets pre-incubated with $100 \mu \mathrm{M}$ Ir-3 for $10 \mathrm{~min}$ and washed two times with Tyrode solution were not significantly different from those of platelets pre-incubated with the solvent control (0.1\% DMSO) under equivalent conditions (Fig. 4A), preliminarily indicating that the effects of Ir-3 on platelet aggregation are reversible and non-cytotoxic. Furthermore, the LDH results revealed that Ir-3 $(20,50$, and $100 \mu \mathrm{M})$ incubated with platelets for $20 \mathrm{~min}$ did not significantly increase LDH activity or exert cytotoxic effects on platelets (Fig. 4B), demonstrating that Ir-3 does not affect platelet permeability 
A

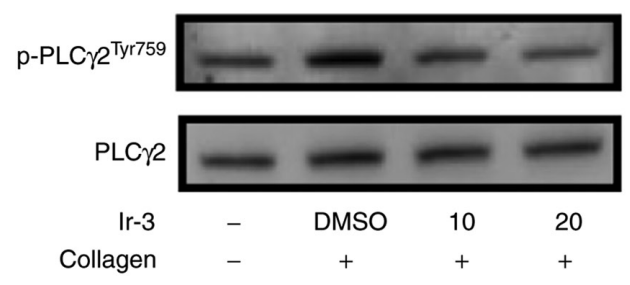

B

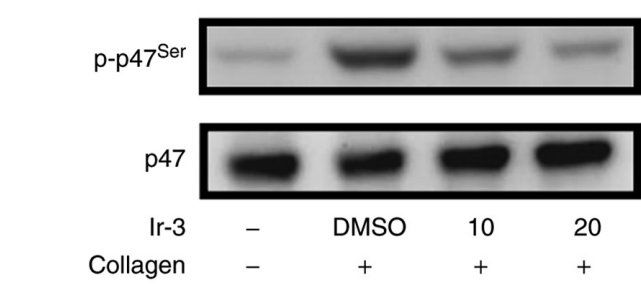

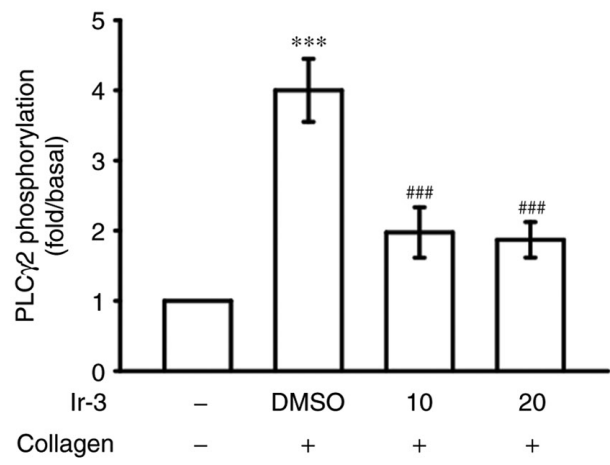

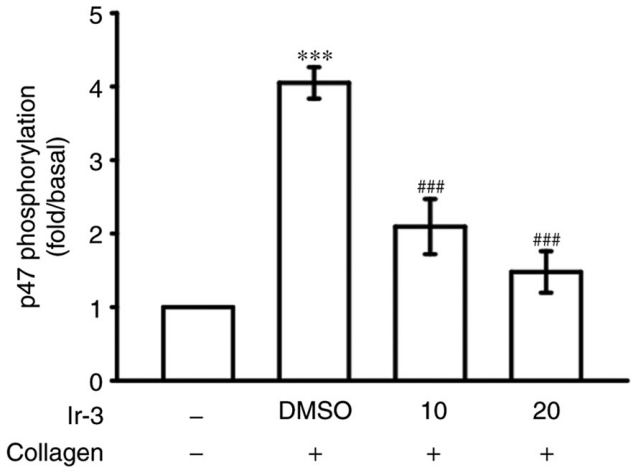

C

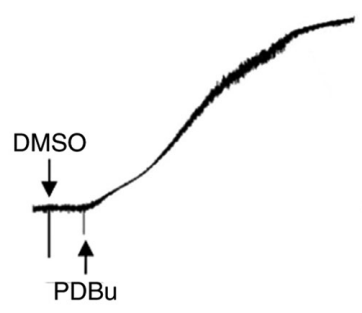

D

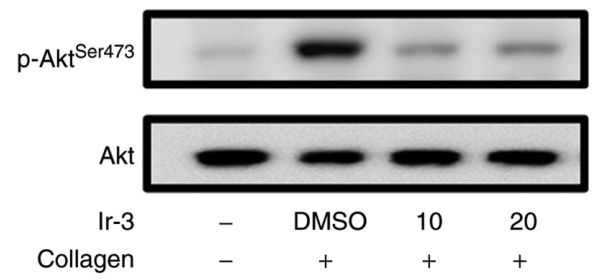

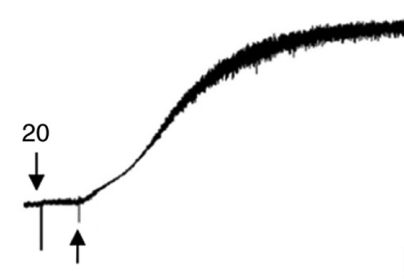

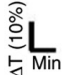

Figure 5. Inhibitory effects of Ir-3 on PLC $\gamma 2$, PKC, and Akt activation in platelets. Washed platelets were preincubated with the solvent control (0.1\% DMSO) or Ir-3 (10 and $20 \mu \mathrm{M}$ ) and subsequently treated with $1 \mu \mathrm{g} / \mathrm{ml}$ collagen or $150 \mathrm{nM}$ PDBu to induce (A) PLC $\gamma 2$ and (B) PKC activation (pleckstrin phosphorylation) or (C) platelet aggregation and (D) Akt activation. The profiles in section C are representative of four independent experiments. Data are presented as the mean \pm standard error of the mean $(\mathrm{n}=4) .{ }^{* * *} \mathrm{P}<0.001$ vs. resting control and ${ }^{\# \# *} \mathrm{P}<0.001$ vs. the DMSO-treated group. PLC $\gamma 2$, phospholipase $\mathrm{C} \gamma 2 ; \mathrm{PKC}$, protein kinase C; Akt, protein kinase B.

or induce platelet cytolysis. Furthermore, $100 \mu \mathrm{M}$ SQ22536, an adenylate cyclase inhibitor, and $10 \mu \mathrm{M}$ ODQ, a guanylate cyclase inhibitor, significantly reversed the inhibition of collagen-induced platelet aggregation mediated by $1 \mu \mathrm{M}$ $\mathrm{PGE}_{1}$ or $10 \mu \mathrm{M}$ NTG (Fig. 4C and D). Neither SQ22536 nor ODQ significantly reversed the inhibition of collagen-induced platelet aggregation mediated by $20 \mu \mathrm{M}$ Ir-3 (Fig. 4C and D), indicating that the mechanisms of Ir-3-mediated inhibition of platelet aggregation are independent of increasing cyclic nucleotide formation.
Regulatory character of Ir-3 on the PLC $\gamma 2 / P K C$ cascade and Akt activation. PLCs hydrolyze phosphatidylinositol 4,5-bisphosphate to generate the secondary messengers inositol 1,4,5-trisphosphate $\left(\mathrm{IP}_{3}\right)$ and diacylglycerol (DAG). $\mathrm{IP}_{3}$ triggers relative $\left[\mathrm{Ca}^{2+}\right]$ mobilization and DAG activates $\mathrm{PKC}$, yielding a $\sim 47-\mathrm{kDa}$ protein that is predominantly phosphorylated ( $\mathrm{p} 47$ protein; pleckstrin) and leads to the ATP release reaction (13). Fig. 3A and B illustrate the inhibitory effects of Ir-3 against ATP release and relative $\left[\mathrm{Ca}^{2+}\right]$ mobilization. The influence of Ir-3 on the phosphorylation 
A
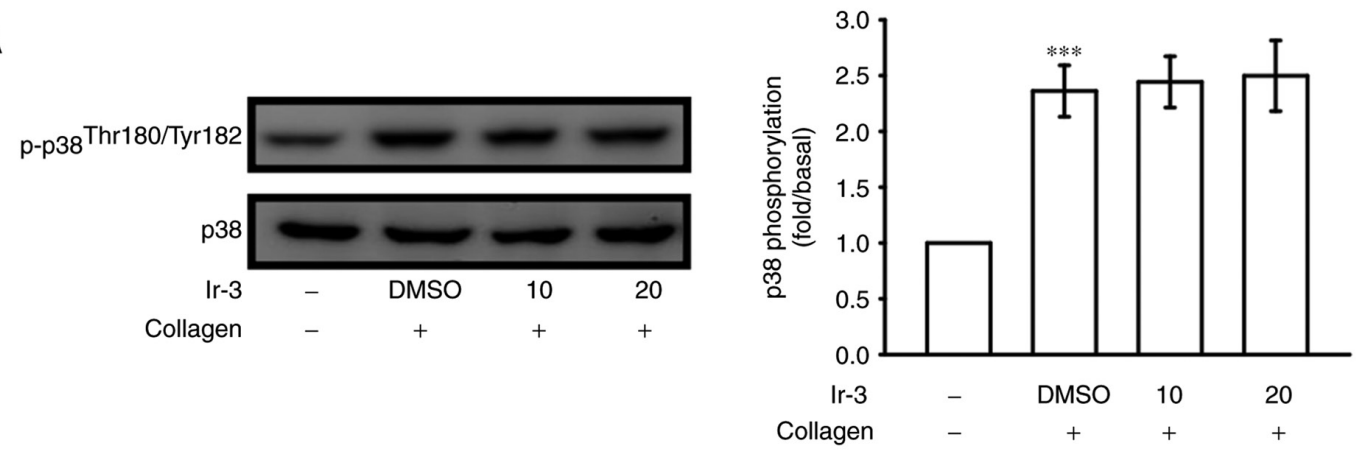

B
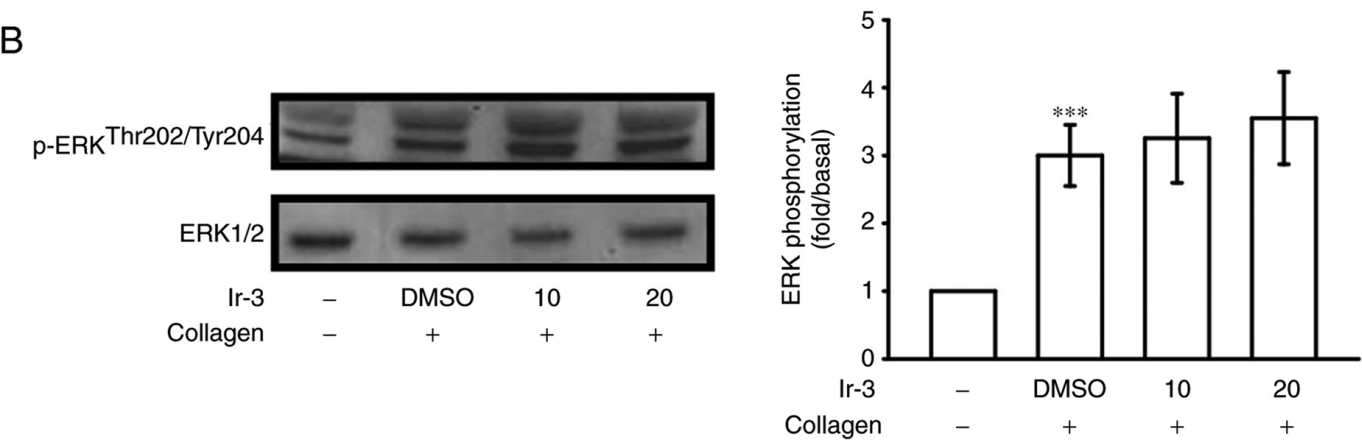

C
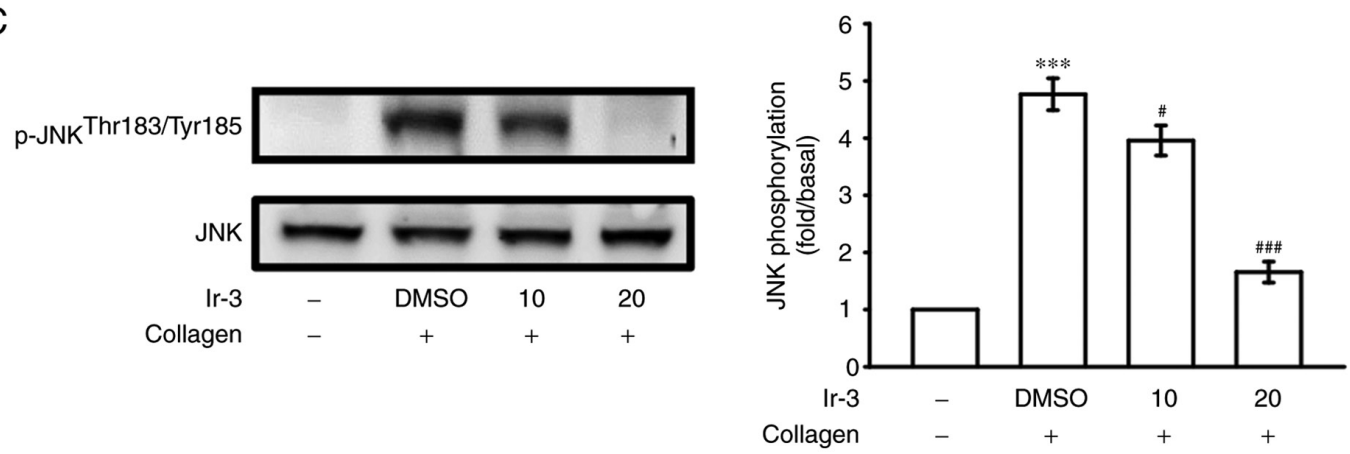

Figure 6. Effects of Ir-3 on p38 MAPK, ERKs, and JNK1 phosphorylation in collagen-activated platelets. Washed platelets (1.2x10 ${ }^{9}$ cells/ml) were pretreated with the solvent control $(0.1 \%$ DMSO) or Ir-3 (10 and $20 \mu \mathrm{M})$ and then treated with $1 \mu \mathrm{g} / \mathrm{ml}$ collagen to stimulate platelet activation. Platelets were collected, and their subcellular extracts were analyzed to determine the levels of (A) p38 MAPK (n=3) (B) ERKs (n=3) and (C) JNK1 phosphorylation (n=4). Data are presented as the mean \pm standard error of the mean. ${ }^{* * * *} \mathrm{P}<0.001$ vs. resting control and ${ }^{\# \# \#} \mathrm{P}<0.001$ vs. the DMSO-treated group. MAPK, mitogen-activated protein kinase; ERK, extracellular signal-regulated kinase; JNK, c-Jun N-terminal kinase.

of the PLC $\gamma 2-\mathrm{PKC}$ signaling cascade was then investigated further. At 10 and $20 \mu \mathrm{M}$, Ir-3 significantly reduced PLC $\gamma 2$ phosphorylation and PKC activation (pleckstrin phosphorylation) in collagen-stimulated platelets compared with the DMSO control (Fig. 5A and B). However, Ir-3 had no significant effects on platelet aggregation stimulated by $150 \mathrm{nM}$ PDBu, a PKC activator (Fig. 5C), indicating that Ir-3 does not directly disturb PKC activation but may interfere with upstream regulators of PKC, including PLC $\gamma 2$. Akt is a serine/threonine-specific protein kinase that serves a key function in multiple cellular processes, including platelet activation, cell proliferation, apoptosis and cell migration (14). Ir-3 (10 and $20 \mu \mathrm{M})$ significantly inhibited collagen-induced Akt phosphorylation (Fig. 5D) compared with the DMSO control, demonstrating the involvement of Akt signaling pathway inhibition in Ir-3-mediated inhibition of platelet activation.

Inhibitory effects of Ir-3 on p38 MAPK, ERKs and JNKI phosphorylation. To investigate the inhibitory mechanisms of Ir-3 in platelet activation, several signaling molecules of the MAPK phosphorylation pathway were evaluated. MAPKs, including p38 MAPK, ERKs, and JNKs, regulate major cellular responses in eukaryotic organisms and contribute to cell proliferation, migration, differentiation, and apoptosis (15). ERKs, JNK1, and p38 MAPK have been identified in platelets (16). Although collagen-induced p38 MAPK and ERK phosphorylation was unaffected by Ir-3, JNK1 phosphorylation was suppressed by 10 and $20 \mu \mathrm{M}$ Ir-3 in a concentration-dependent manner (Fig. 6). These results suggest that only JNK1 may be involved in the antiplatelet activity of Ir-3.

Determination of the function of the $\mathrm{OH}$ radical $(\mathrm{OH} \cdot)$ in the Ir-3-mediated inhibition of platelet aggregation through ESR spectrometry. An ESR signal indicative of $\mathrm{OH} \cdot$ formation was observed in collagen-stimulated platelet suspensions and Fenton reaction solution (cell-free system; Fig. 7A and B). A typical $\mathrm{OH} \cdot \operatorname{signal}\left(\mathrm{a}^{\mathrm{N}}=\mathrm{a}^{\mathrm{H}}=14.8 \mathrm{G}\right)$ and a long-lived $\mathrm{g}=2.005$ 

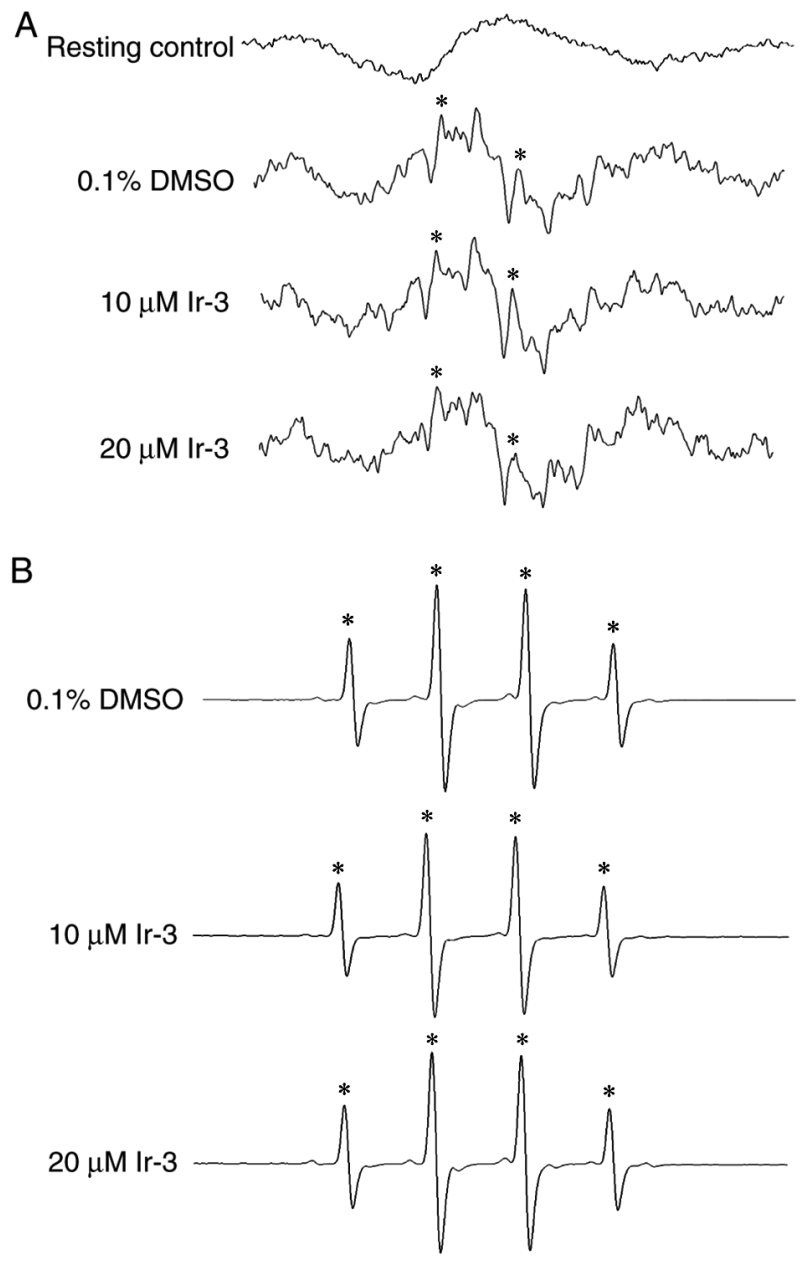

Figure 7. Effect of Ir-3 on $\mathrm{OH} \cdot$ formation in human platelets or Fenton reaction solution, investigated through ESR spectrometry. (A) Washed platelets were pre-incubated with Tyrode's solution (resting control) or treated with $0.1 \%$ DMSO, 10 or $20 \mu \mathrm{M}$ Ir-3. Collagen $(1 \mu \mathrm{g} / \mathrm{ml})$ was added to trigger $\mathrm{OH}^{\text {. }}$ formation. (B) For the cell-free Fenton reaction study, 0.1\% DMSO, 10 or $20 \mu \mathrm{M}$ Ir-3 was pre-incubated with the solution, and DMPO was then added for the ESR experiments. Profiles are representative of four independent experiments. An asterisk $\left(^{*}\right)$ indicates $\mathrm{OH} \cdot$ formation. $\mathrm{OH} \cdot \mathrm{OH}$ radical; ESR electron spin resonance; DMPO, 5,5-dimethyl-1-pyrroline $\mathrm{N}$-oxide.

radical detectable using the spin trap DMPO were observed in collagen-stimulated platelets, whereas this signal was not detected in resting platelets (Fig. 7A and B). Treatment with 10 and $20 \mu \mathrm{M}$ Ir-3 did not notably diminish the $\mathrm{OH} \cdot$ signals in collagen-stimulated platelet suspensions or Fenton reaction solution (Fig. 7), suggesting that the Ir-3-mediated inhibition of platelet activation may not be mediated through the reduction of free radical formation.

\section{Discussion}

Platelet activation is associated with thrombotic events in patients with cancer (17). Chemotherapeutics may amplify this effect and stimulate vascular thromboembolic events (VTEs) by aggravating endothelial damage, increasing platelet aggregation and increasing oxidative damage, leading to vascular toxicity (18). Among Pt-based chemotherapeutics, cisplatin has a high prevalence of treatment-associated VTEs (19). Gemcitabine in combination with a Pt-based agent is associated with increased thrombotic and vascular side effects $(20,21)$. Therefore, research has focused on the development of novel metal-based agents for the inhibition of platelet activation to treat vascular disease, reduce toxic side effects and overcome $\mathrm{Pt}$ resistance. To the best of our knowledge, the present study is the first to demonstrate that Ir-3, an unique synthetic Ir (III)-derived compound, displays effective antiplatelet activity in human platelets in addition to its antitumor activity.

Platelets adhere to subendothelial matrix proteins, including collagen, thus altering their shape and releasing their granular contents, which include ATP, $\mathrm{Ca}^{+2}$ and P-selectin. Intracellular $\left[\mathrm{Ca}^{2+}\right]$ mobilize as a result of several agonists, including collagen, thrombin and AA, to phosphorylate the $\mathrm{Ca}^{2+} /$ calmodulin-dependent myosin light chain $(20 \mathrm{kDa})$, which is involved in the release of serotonin and ATP (22), and platelet aggregation. Therefore, the inhibition of $\left[\mathrm{Ca}^{2+}\right]$ mobilization and ATP production are crucial for assessing the antiplatelet effects of a compound. In the present study, Ir-3 inhibited platelet aggregation to different degrees, depending on the agonist used (either collagen, U46619, AA or thrombin), indicating that Ir-3 did not act at the specific individual receptors of these agonists. Therefore, Ir-3 may exert its inhibitory effects on stimulated platelets through a common signaling cascade.

Furthermore, platelet activation by collagen, substantially alters PLC expression, and results in $\mathrm{IP}_{3}$ and DAG production, which activates PKC and consequently induces p47 phosphorylation (13). PKC activation triggers specific responses, assisting in the transmission of activating signals in different cellular compartments. The PLC $\gamma$ family is comprised of the isozymes PLC $\gamma 1$ and PLC $\gamma 2$, with PLC $\gamma 2$ being involved in collagen-dependent signaling in platelets (23). Ir-3 diminished collagen-induced PLC $\gamma 2$-PKC activation; however, Ir-3 was not effective on PKC activation as it did not inhibit $\mathrm{PDBu}$-induced platelet aggregation, suggesting that the Ir-3-mediated inhibition of platelet activation involves PLC $\gamma 2$ downstream signaling. This result also explains how Ir-3 was more efficacious at inhibiting platelet aggregation induced by collagen than that induced by thrombin, U46619, and AA.

Cyclic nucleotides are important modulators of platelet activation (24), and intracellular cyclic AMP- and cyclic GMP are involved in the inhibition of human platelet activation. At elevated levels, cyclic nucleotides prevent several platelet responses and reduce $\left[\mathrm{Ca}^{2+}\right]$ levels through $\mathrm{Ca}^{2+}$ uptake by the dense tubular system, thereby suppressing PLC and PKC activation (24). Therefore, cyclic AMP and cyclic GMP synergistically inhibit platelet activation. Furthermore, neither SQ22536, an inhibitor of adenylate cyclase, nor ODQ, an inhibitor of guanylate cyclase, significantly reversed the Ir-3-mediated inhibition of collagen-induced platelet aggregation. Therefore, the Ir-3-mediated mechanisms were independent of increasing cyclic nucleotide formation in platelets.

Akt is a downstream molecule of phosphoinositide 3-kinase (PI3K). Akt-deficient mice reported defective effects in agonist-induced platelet activation, suggesting that Akt regulates platelet activation, and such regulation may have consequences concerning thrombosis $(14,25)$. Therefore, selective inhibitors of Akt isoforms or its activating proteins, including individual PI3K isoforms, may be attractive 
antithrombotic therapy targets (14). In addition, MAPKs are activated by specific MAPK kinases (MEKs). Specifically, MEK1/2, MEK3/6 and MEK4/7 activate ERKs, p38 MAPK and JNKs, respectively (26). Cytosolic phospholipase $\mathrm{A}_{2}$ $\left(\mathrm{cPLA}_{2}\right)$ is a substrate of p38 MAPK activity induced by various agonists, including von Willebrand factor (vWF) and thrombin (27). Therefore, p38 MAPK is essential for cPLA stimulation and AA release (28). This may explain how Ir-3 was less able to inhibit p38 MAPK activation and thrombin- or AA-stimulated platelet aggregation. ERK activation is involved in platelet aggregation but requires prior ATP release, which triggers a $\mathrm{P}_{2} \mathrm{X}_{1}$-mediated $\mathrm{Ca}^{2+}$ influx and activates ERKs, thereby increasing the phosphorylation of myosin light-chain kinase (27). JNK1 is the most recently identified MAPK in platelets, and therefore its activation status and function are poorly established. It is activated by several agonists, including thrombin, vWF, collagen, and ADP (27). In addition, a previous study demonstrated that an increased bleeding time, decreased integrin $\alpha_{\text {IIb } \beta 3}$ activation and severe granule secretion impairment occur in $\mathrm{JNK}^{-/}$platelets (29). Therefore, the inhibition of JNK phosphorylation may serve an important function in platelet activation. In accordance with these results, the results of the present study demonstrated that Ir-3 markedly inhibited collagen-induced JNK1 phosphorylation.

Reactive oxygen species produced through platelet activation, including hydrogen peroxide and $\mathrm{OH} \cdot$, may affect cells that they come in contact with, for example endothelial cells, thereby increasing platelet reactivity during thrombus formation. Free radical species act as secondary signals that increase $\left[\mathrm{Ca}^{2+}\right]$ levels during the initial phase of platelet activation, and $\mathrm{PKC}$ is involved in the receptor-mediated production of free radicals in platelets (30). In addition, hydrogen peroxide produced by platelets is converted into $\mathrm{OH}$, because platelet aggregation is inhibited by $\mathrm{OH} \cdot$ scavengers (30). The ESR spectrometry results from the present study provide direct evidence that $\mathrm{Ir}-3$ does not significantly reduce $\mathrm{OH} \cdot$ formation in collagen-stimulated platelet suspensions and Fenton reaction solution. In addition, Ir tissue distribution and excretion in rats following sub-chronic oral administration of Ir (III) chloride hydrate $(1-1,000 \mathrm{ng} / \mathrm{ml})$ for 90 days was previously determined (31). Concerning the distribution, the majority of Ir was located in the kidney and spleen, and smaller amounts were observed in the lungs, liver and brain. Notably, a slight increase of brain Ir levels was observed with increasing doses of Ir, indicating the ability of Ir to cross the blood-brain barrier. Furthermore, the dose-dependent increase of Ir levels in the serum demonstrated that the Ir was distributed in the blood compartment. For excretion, the body clearance of Ir primarily took place by elimination via feces, and this was also dose-associated (31).

In conclusion, the results of the present study demonstrate that the novel Ir-3 compound inhibited platelet activation by inhibiting signaling pathways, including the PLC $\gamma 2-\mathrm{PKC}$ cascade, and subsequently suppressing Akt and JNK1 activation. These alterations reduced granule secretion (including ATP release, $\left[\mathrm{Ca}^{2+}\right]$ levels and surface $\mathrm{P}$-selectin expression) and ultimately inhibited platelet aggregation. However, additional studies are required to investigate the involvement of other unidentified mechanisms of the Ir-3-mediated inhibition of platelet activation. Nevertheless, Ir-3 represents a potential chemotherapeutic agent for the treatment of cancer. In addition, it may be used as an antiplatelet agent for treating thromboembolic disorders or the interplay between platelets and tumor cells which contributes to tumor cell proliferation and progression.

\section{Acknowledgements}

The present study was supported by grants from the Ministry of Science and Technology of Taiwan (MOST 104-2622-B-038-003, MOST 104-2320-B-038-045-MY2 and MOST 106-2320-B-038-012), Shin Kong Wu Ho-Su Memorial Hospital-Taipei Medical University (SKH-TMU-103-01), and the University Grants Commission, India (MRP-MAJOR-CHEM-2013-5144; 69/2014 F. No. 10-11/12UGC).

\section{Competing interests}

The authors declare that they have no competing interests.

\section{References}

1. Jayakumar T, Yang CH, Geraldine P, Yen TL and Sheu JR: The pharmacodynamics of antiplatelet compounds in thrombosis treatment. Expert Opin Drug Metab Toxicol 12: 615-632, 2016.

2. Belloc C, Lu H, Soria C, Fridman R, Legrand Y and Menashi S: The effect of platelets on invasiveness and protease production of human mammary tumor cells. Int J Cancer 60: 413-417, 1995.

3. Felding-Habermann B, Ooole TE, Smith JW, Fransvea E, Ruggeri ZM, Ginsberg MH, Hughes PE, Pampori N, Shattil SJ, Saven A, et al: Integrin activation controls metastasis in human breast cancer. Proc Natl Acad Sci USA 98: 1853-1858, 2001.

4. Boucharaba A, Serre CM, Gres S, Saulnier-Blache JS, Bordet JC, Guglielmi J, Clezardin P and Peyruchaud O: Platelet-derived lysophosphatidic acid supports the progression of osteolytic bone metastases in breast cancer. J Clin Invest 114: 1714-1725, 2004.

5. Iavicoli I, Cufino V, Corbi M, Goracci M, Caredda E, Cittadini A, Bergamaschi A and Sgambato A: Rhodium and iridium salts inhibit proliferation and induce DNA damage in rat fibroblasts in vitro. Toxicol In Vitro 26: 963-969, 2012.

6. Iavicoli I, Fontana L, Marinaccio A, Alimonti A, Pino A, Bergamaschi A and Calabrese EJ: The effects of iridium on the renal function of female wistar rats. Ecotoxicol Environ Safe 74: 1795-1799, 2011.

7. Romero-Canelón I and Sadler PJ: Next-generation metal anticancer complexes: Multitargeting via redox modulation. Inorg Chem 52: 12276-12291,2013.

8. Yellol J, Pe'́rez SA, Buceta A, Yellol G, Donaire A, Szumlas P, Bednarski PJ, Makhloufi G, Janiak C, Espinosa A and Ruiz J: Novel C,N-cyclometalated benzimidazole ruthenium(II) and iridium(III) complexes as antitumor and antiangiogenic agents: A structure-activity relationship study. J Med Chem 58: 7310-7327, 2015.

9. Schmitt F, Donnelly K, Muenzner JK, Rehm T, Novohradsky V, Brabec V, Kasparkova J, Albrecht M, Schobert R and Mueller T: Effects of histidin-2-ylidene vs. imidazol-2-ylidene ligands on the anticancer and antivascular activity of complexes of ruthenium, iridium, platinum, and gold. J Inorg Biochem 163: 221-228, 2016.

10. Sheu JR, Lee CR, Lin CH, Hsiao G, Ko WC, Chen YC and Yen MH: Mechanisms involved in the antiplatelet activity of staphylococcus aureus lipoteichoic acid in human platelets. Thromb Haemost 83: 777-784, 2000.

11. Chou DS, Hsiao G, Shen MY, Tsai YJ, Chen TF and Sheu JR: ESR spin trapping of a carbon-centered free radical from agonist-stimulated human platelets. Free Radic Biol Med 39: 237-248, 2005.

12. Harrison P and Cramer EM: Platelet alpha-granules. Blood Rev 7: 52-62, 1993. 
13. Singer WD, Brown HA and Sternweis PC: Regulation of eukaryotic phosphatidylinositol-specific phospholipase C and phospholipase D. Annu Rev Biochem 66: 475-509, 1997.

14. Woulfe DS: Akt signaling in platelet and thrombosis. Expert Rev Hematol 3: 81-91, 2010.

15. Roux PP and Blenis J: ERK and p38 MAPK-activated protein kinases: A family of protein kinases with diverse biological functions. Microbiol Mol Biol Rev 68: 320-344, 2004.

16. Bugaud F, Nadal-Wollbold F, Levy-Toledano S, Rosa JP and Bryckaert M: Regulation of c-jun-NH2 terminal kinase and extracellular-signal regulated kinase in human platelets. Blood 94: 3800-3805, 1999.

17. Lip GY, Chin BS and Blann A: Cancer and the prothrombotic state. Lancet Oncol 3: 27-34, 2002.

18. Ferroni P, Della-Morte D, Palmirotta R, McClendon M, Testa G Abete P, Rengo F, Rundex T, Guadagni F and Roselli M: Platinum-based compounds and risk for cardiovascular toxicity in the elderly: Role of the antioxidants in chemoprevention. Rejuvenation Res 14: 293-308, 2011.

19. Jafri $\mathrm{M}$ and Protheroe A: Cisplatin-associated thrombosis. Anticancer Drugs 19: 927-929, 2008.

20. Barni S, Labianca R, Agnelli G, Bonizzoni E, Verso M Mandalà M, Brighenti M, Petrelli F, Bianchini C, Perrone T and Gasparini G: Chemotherapy-associated thromboembolic risk in cancer outpatients and effect of nadroparin thromboprophylaxis: Results of a retrospective analysis of the PROTECHT study. J Transl Med 20: 179, 2011

21. Dasanu CA: Gemcitabine: Vascular toxicity and prothrombotic potential. Expert Opin Drug Safe 7: 703-716, 2008.

22. Kaibuchi K, Sano K, Hoshijima M, Takai Y and Nishizuka Y: Phosphatidylinositol turnover in platelet activation; calcium mobilization and protein phosphorylation. Cell Calcium 3 : 323-335, 1982.

23. Ragab A, Séverin S, Gratacap MP, Aguado E, Malissen M, Jandrot-Perrus M, Malissen B, Ragab-Thomas J and Payrastre B Roles of the C-terminal tyrosine residues of LAT in GP VI-induced platelet activation: Insights into the mechanism of PLC gamma 2 activation. Blood 110: 2466-2474, 2007.
24. Walter U, Eigenthaler M, Geiger J and Reinhard M: Role of cyclic nucleotide-dependent protein kinases and their common substrate VASP in the regulation of human platelets. Adv Exp Med Biol 344: 237-249, 1993.

25. Chen J, De S, Damron DS, Chen WS, Hay N and Byzova TV: Impaired platelet responses to thrombin and collagen in AKT-1-deficient mice. Blood 104: 1703-1710, 2004.

26. Chang L and Karin M: Mammalian MAP kinase signaling cascades. Nature 410: 37-40, 2001

27. Adam F, Kauskot A, Rosa JP and Bryckaert M: Mitogen-activated protein kinases in hemostasis and thrombosis. J Thromb Haemost 6: 2007-2016, 2008.

28. Canobbio I, Reineri S, Sinigaglia F, Balduini C and Torti M: A role for $\mathrm{p} 38$ MAP kinase in platelet activation by von Willebrand factor. Thromb Haemost 91: 102-110, 2004

29. Adam F, Kauskot A, Nurden P, Sulpice E, Hoylaerts MF, Davis RJ, Rosa JP and Bryckaert M: Platelet JNK1 is involved in secretion and thrombus formation. Blood 115: 4083-4092, 2010.

30. Wachowicz B, Olas B, Zbikowska HM and Buczyński A: Generation of reactive oxygen species in blood platelets. Platelets 13: 175-182, 2002.

31. Iavicoli I, Fontana L, Bergamaschi A, Conti ME, Pino A, Mattei D, Bocca B and Alimonti A: Sub-chronic oral exposure to iridium (III) chloride hydrate in female wistar rats: Distribution and excretion of the metal. Dose-Response 10: 405-414, 2012.

This work is licensed under a Creative Commons Attribution-NonCommercial-NoDerivatives 4.0 International (CC BY-NC-ND 4.0) License. 